Student Success

ISSN: 2205-0795

Volume 6, Issue 2, pp. 43-52

August 2015

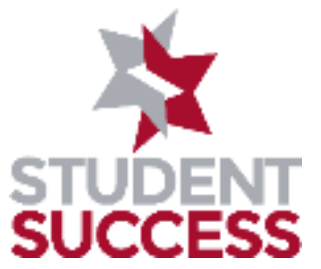

\title{
Identity theory as a theoretical framework to understand attrition for university students in transition
}

\author{
Robert Whannell and Patricia Whannell
}

University of New England, Armidale, Australia

\section{Abstract*}

There has been extensive research done with a view to explaining the processes of transition into tertiary study and the factors that may be associated with student attrition. This paper consolidates the authors' research in relation to the transition of students into adult and tertiary bridging programs and undergraduate university study and presents an alternative approach to the use of objective conditions such as financial challenges and first-in-family status in explaining the attrition phenomenon. Identity theory is used as the basis to develop a theoretical framework that will assist educators working in these areas to engage more fully with and assist students to develop the academic and scholarly identity necessary to sustain appropriate and effective academic behaviours during the transition into tertiary education.

*This article was first presented at the 2015 STARS Conference in Melbourne, Australia in July 2015 and was selected via the peer review process as one of the top-rated papers. The authors have kindly given their permission to have this article published in the conference issue of the Journal and it has undergone a further review by the editors to confirm it aligns with the Journal format.

Please cite this article as:

Whannell, R. \& Whannell, P. (2015). Identity theory as a theoretical framework to understand attrition for university students in transition. Student Success, 6(2), 43-52. doi: 10.5204/ssj.v6i2.286

This article has been peer reviewed and accepted for publication in Student Success. Please see the Editorial Policies under the 'About' section of the Journal website for further information.

Student Success: A journal exploring the experiences of students in tertiary education

(cc) $\mathrm{BY}$ This work is licensed under a Creative Commons Attribution 4.0 Licence. As an open access journal, articles are free to use, with proper attribution, in educational and other non-commercial settings. ISSN: 2205-0795 


\section{Introduction}

In the current age of massification of education (Gibbons et al., 2004), student cohorts in the first year of university present a very diverse group, both in cultural and academic terms. Attrition from undergraduate study at Australian universities reaches over $30 \%$ at some institutions (Allen, 2010), with rates even higher in the first year of study. One of the challenges facing those engaged in addressing university student attrition and improving engagement with study is in understanding why a particular individual elects to discontinue their tertiary study. An examination of the literature relating to the reasons why students drop out of undergraduate study allows the identification of a number of external objective factors involved in the decision. Commonly cited factors include being the first-in-family to attend university (e.g. Collier \& Morgan, 2008; Jardine \& Krause, 2005; Luzeckyj, King, Scutter, \& Brinkworth, 2011), financial pressure and the time pressures associated with outside employment (e.g. Krause, Hartley, James, \& McInnis, 2005; Leppel, 2002; McMillan, 2005).

It is the case, however, that undergraduate students do persist and are able to complete their program of study in the face of what may seem insurmountable objective challenges. The capacity to continue a course of action in the face of continued adversity in this way suggests that human behaviour is not simply a reaction to external, objective conditions. Rather, behaviour is the product of the interplay of objective conditions with the particular subjective, internal psychology of a given individual (Bronfenbrenner, 2009; Deci \& Ryan, 1985). For this reason, any reasonably sophisticated approach to the question of undergraduate student behaviour relating to attrition/retention and engagement must incorporate some form of theoretical framework incorporating the psychology of the individual. It must look beyond the identification of objective factors that demonstrate statistically significant differences in a particular behaviour e.g. attrition.

This paper will present a theoretical framework, based on identity theory that will assist educators in understanding university attrition and engagement at the level of the individual. It commences with a description of the origins of an individual's social and selfidentity. A model incorporating social context, identity, emotional commitment to identity and role is then presented. The paper concludes with a discussion of a number of implications for practice based upon the theoretical framework for university academic and professional staff engaged in supporting and engaging students in university transition.

\section{Identity, roles and emotional commitment}

The self-concept may be defined as "the totality of a complex, organised, and dynamic system of learned beliefs, attitudes and opinions that each person holds to be true about his or her personal existence" (Purkey, 1988). Terry, Hogg, and White (1999) define self-identity as "a collection of identities that reflects the roles that a person occupies in the social structure" (p. 227). They also identify a close link between self-identity and behaviours which are demonstrated in the wider social context. Identity theory is proposed as providing "clear justification for the inclusion of self-identity as a predictor of intention, given that, in both the theories of reasoned action and planned behaviour, intention is regarded as the most proximal predictor of behaviour" (Terry et al., $p$. 227). The more developed the identity structure is, "the more aware individuals appear to be of their own uniqueness and similarity to others and of their own strengths and weaknesses in making their way in the world" (Marcia, 1980, p. 159).

The relationship between the planned behaviour of the individual and self-identity has been established in a number of studies across 
a range of areas, including eating behaviours (Sparks \& Guthrie, 1998; Sparks \& Shepherd, 1992), recycling (Terry et al., 1999) and blood donation (Callero, 1985). In a review of the literature relating to the self-identity construct, Stryker and Burke (2000) identified two contrasting approaches. Self-identity was described as either focusing on the linkages of social structures with identities or on the internal process of self-verification. They concluded that

persons typically are embedded in multiple role relationships in multiple groups and they hold multiple identities. These multiple roles and multiple identities may reinforce one another, but perhaps more often do not. When they do not, they introduce identity competition or conflicts that complicate the reciprocal relationships between commitments, identity salience, identity standards, and self-relevant perceptions.

$$
\text { (p. 290) }
$$

Tertiary students attempting to commence study would appear to be prime candidates for such a conflict of identity to occur. For many students, entering university involves substantial changes in their living and education environments. University transition may involve changes in residence, where the student was previously residing with parents and may now need to reside away from home for the first time, financial challenges associated with funding their own living expenses, and changes in the educational environment where the student is now required to be much more self-directed and self-sufficient. In the case of mature age students who have been absent from education for a substantial period and who are well established in existing long term social, family and work contexts, the individual is attempting to assume the new identity and role required as a university student. Students who have had negative experiences in secondary school and who may have experienced a disengagement from education, are attempting to re-engage with a role which may have substantial negative emotional associations. In these cases, it would seem that the role and identity conflicts described by Styker and Burke (2000) would have a high probability of occurring.

Of particular relevance to the current examination is the association by Styker and Burke (2000) of identity with commitment. This relationship was also described by Hoelter (1983) who established that identity salience was "positively affected by (1) the degree of commitment to its respective role and (2) the degree to which its respective role is positively evaluated with regard to one's performance" ( $p$. 140). It would be expected that where a student experienced difficulty in performing the role of a successful university student, their commitment to that identity and to the completion of tertiary study would be adversely influenced.

An associated problem for the aspiring undergraduate student is that the adoption and development of the new identity as a university student occurs relatively slowly. Burke (2006) describes a "dynamic view of identities as always changing (though slowly) in response to the exigencies of the situation. Insofar as an identity cannot change the situation...it adapts slowly, gaining control where it can, and adapting where it must" (p. 93). This slow rate of change of identity is also described by Marcia (1980).

Burke and Reitzes (1991), in a study of 640 undergraduate college students in the USA, describe a close relationship between commitment, identity and activity. They argue that:

Commitment connects an individual to an identity. In this view, commitment does not link a person to consistent lines of activity, other role partners, or organizations, but to a stable set of self-meanings. These stable selfmeanings, in turn produce consistent lines of activities. 
(p. 239)

The link between the individual's identity as a university student and the experience at the time of return of the first assessment task has previously been described in the following terms:

As a lecturer, Jo's concern about returning the first assignment centred on her knowledge of its importance as a stage in the creation of a scholarly identity. She understood that, for some, the first marked assignment would be a positive affirmation, while for others, a disappointing work would pose a challenge that some would choose not to meet.

(Debenham \& May, 2005, p. 90)

The ability of a student to identify themselves in the role of a tertiary student has been described previously in the academic literature. The primary barriers identified are the social class, gender and/or age of the student (Baxter \& Britton, 2001; Tett, 2000; Waller, 2006; Wiley, 1991).

Ingleton (1999) describes the role of emotions in the educational environment in the following terms:

The disposition to learn has its basis in social relationships. Arising from those relationships are the emotions of pride and shame which play a key role in the development of identity and self-esteem. The dynamics of pride and shame and identity, in the context of experiences of success and failure, may dispose students to act positively or negatively towards learning.

\section{(p. 1)}

Ingleton identifies the relationships with teachers, peers and parents as giving rise to the emotions involved in the educational experience. The process of the development of these emotions is viewed as "the basis of decision-making, conscious or unconscious, about immediate or future action" (p. 3). He concludes that "past emotions and memories may be experienced consciously or unconsciously in the present, and are ongoing in the maintenance of self-esteem and identity" (p. 9). The association between goal commitment, emotion and identity has also been described by other researchers. Pekrun, Goeta, Titz, and Perry (2002) concluded that "academic emotions are closely tied to students' selfappraisals of competence and control in the academic domain, to the values and goals they attach to learning and achievement, and to classroom instruction and social environments affecting control, values and goals" (p. 103).

\section{Identity, roles and emotional commitment theoretical framework}

The literature examined in relation to identity theory proposes three aspects that must be considered in addition to the actual academic identity of an individual: the social context of the individual, the emotional commitment to the identity and the associated role. When viewed through the construct of identity theory (Burke, 2006; Burke \& Reitzes, 1981, 1991; Styker \& Burke, 2000), these components may be modelled theoretically as shown in Figure 1.

The emotionality involved is proposed as being associated with the identity, rather than the associated role (Burke \& Reitzes, 1991). The level of emotional commitment to the identity is, in turn, influenced by the individual's perception of their regard for their performance of the associated role (Hoelter, 1983). The process of positive identity formation is proposed as following a cyclical path where ongoing successful academic engagement, particularly with assessment and academic staff, progressively strengthens the university student identity. A strengthening of the university student identity, in turn, is seen as an increase in positive academic behaviours. Where a negative experience occurs, such as a poor assessment mark or negative staff 


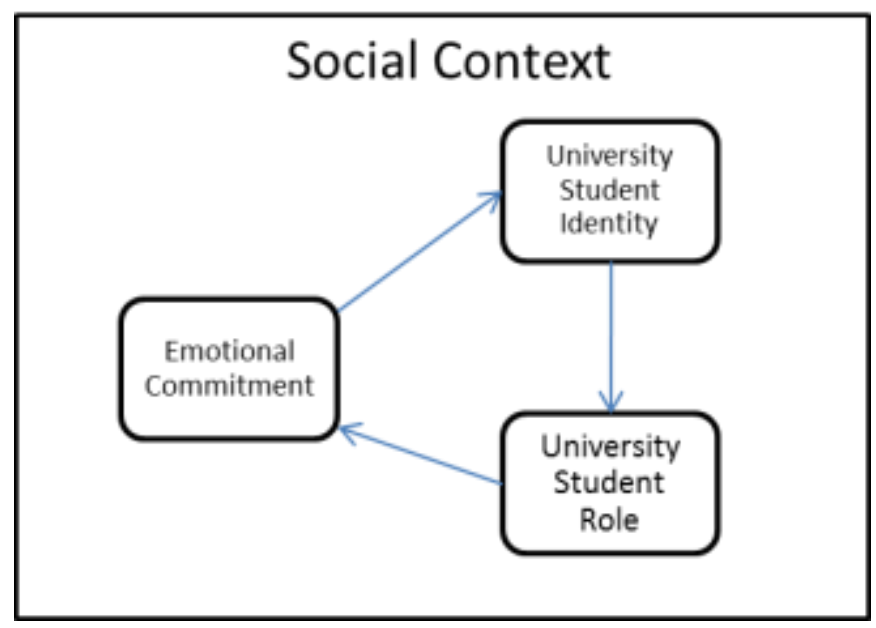

Figure 1: Theoretical model for university student identity formation

interaction, the commitment to the university student identity is reduced. Poor previous educational experiences may also act to exaggerate the effect of such a negative experience. The capacity of a self-fulfilling prophecy, based upon negative previous negative experiences and teacher expectations, to negatively influence the performance of students has been previously demonstrated (Biggs, 2009) and must be considered. Bosma and Kunnen (2001) describe the process of identity development "as an iterative process of person-context transactions" (p. 39) which requires an openness to change on the part of the individual and appropriate environmental support and developmental history. The capacity exists for adult learners returning to tertiary study to change the perspectives that they hold of their academic ability as students to be modified when the opportunity to reflect critically upon their experiences is available (Willans \& Seary, 2007).

There are a number of different identities that may drive initial enrolment in university. It may be the case that an individual has no university student identity at all, but is engaging in the role of a university student based upon some other identity driver. Examples of this would include a student driven by a strongly held dream of being a doctor or engineer, or a student who is attending university in accordance with parental wishes. The capacity of these different identities to support a successful transition into and ongoing attendance at university differ greatly. In the case of the aspiring doctor, completion of university is essential as there is no alternative pathway that will provide access to the profession. On the contrary, a motivator such as parental expectations appears to have a much more limited capacity to support transition, particularly where substantial barriers to transition are experienced and/or the student is at an age where parental influence is being challenged. In situations where students are challenged in their transition into university and appear to be having academic difficulties, it is quite possible that such identity challenges are at play. Addressing purely academic matters without resolving the identity issues in such a situation would have little likelihood of providing a remedy for the student. 
This view explains the important role of the first assessment tasks and early social interactions encountered in the development of a university student identity. These formal assessment tasks, and earlier informal assessment situations, are the first opportunity where students have the opportunity to assess their capacity to perform the role of a university student. Where this experience is not of a positive and confirming nature, the students' emotional commitment to the university student identity may be negatively impacted, particularly where pre-existing negative belief patterns in relation to education are involved. Students whose previous experience of education has been negative, those who question their capacity to perform at an academic level commensurate with university study and those lacking specific career-oriented reasons for attending university would appear to be particularly vulnerable in this situation. Where the damage to the emotional commitment to the university student identity is sufficient, attrition may result.

The model proposed by Wylie $(2004,2005)$ in his study of Australian TAFE students entering university appears particularly relevant to this situation. He proposed that where a negative experience occurs and the academic and/or social self-worth of the student is negatively affected, a spiralling process of disengagement may occur which would be identifiable by an increase in separation behaviour.

\section{Academic self-concept}

A number of researchers have addressed the issues described in this paper through the construct of self-concept. Hattie (2014) identified a number of terms that are used interchangeably with self-concept, including self-identity. Self-concept has been defined as "our perception of ourselves; in specific terms, it is our attitudes, feelings and knowledge about our abilities, skills, appearance, and social acceptability" (Byrne, 1984, p. 429). A number of researchers have established that there are different dimensions to the self-concept construct and that the dimension which is specific to the situation under consideration must be examined (Byrne, 1984; Choi, 2005; Marsh, 1990; Marsh \& Yeung, 1997). These researchers identified a specific dimension relating to the educational environment, namely, academic self-concept. Similarities have been identified between the academic selfefficacy and academic self-concept constructs (Bong \& Clark, 1999; Bong \& Skaalvik, 2003). However, Bong and Skaalvik (2003), while identifying a number of similarities between the constructs, argue that "self-efficacy acts as an active precursor of self-concept development" (p. 1). This view of self-efficacy as facilitating the development of self-concept is also shared by Schunk (1991).

Skaalvik and Skaalvik (2002) identified the frames of reference that students have as being instrumental in their development of their academic self-concept. They propose that academic self-concept is constructed by a process of reference to both internal and external references. The external frames utilised in the process are identified as "(a) school-average ability, (b) class average ability, (c) selected students in class, and (d) selected students outside class" (p. 233). The internal frames of reference used involve the student looking at their own performance in a given subject over time and by comparison of performance between different subjects. In particular, they complete a "comparison of achievements in different school subjects with applied effort in those subjects" (p. 233). This view of the development of academic selfconcept involves only a process which occurs within the classroom. The internal/external frame of reference stance in relation to the development of academic self-concept is also supported by Moller, Pohlmann, Koller, and Marsh (2009).

Academic self-concept has been identified as influencing a number of educational outcomes, including the quality of academic achievement. 
The research demonstrates that prior selfconcept has significant effects on subsequent school-based achievement beyond the substantial effects of prior achievement. This supports the usefulness of academic selfconcept not only as an important outcome variable in its own right but also as a mediating variable that facilitates the attainment of other desirable outcomes.

$$
\text { (Marsh \& Yeung, 1997, p. 50) }
$$

The positive influence of an improved academic self-concept on achievement has also been demonstrated at the tertiary level of education (Choi, 2005; Reynolds, 1988).

In the case of the current discussion, there are two aspects of self-concept which are considered relevant. In the early weeks of attendance at university it is considered that a student who perceives themselves to have a history of relatively poor academic outcomes and who may have been absent from an educational environment for a reasonable period may have difficulty conceiving of themselves as a successful university student. During this period the student is hypothesised to be more susceptible to attrition due to negative comparison with other students, an inability to perform the substantially more challenging and independent role associated with being a university study and to the nature of the institution they are attending. For example, students who previously attended small rural schools may find the nature of the environment in a capital city university catering to many thousands of students a challenge. In this situation, it is not necessarily the challenge to the academic identity that is the source of the problem, but rather, it is directed more towards the capacity of the individual to see themselves as a resident in a large, fast-paced city. Essentially, the individual is hypothesised as being unable to conceptualise themselves as a successful university student and may drop out of the program as a result. The second aspect considered of interest is the vulnerability of their self-concept as a successful university student which arises in their attendance in their first semester of undergraduate study. At this time, the student must co-exist with other students who may exhibit substantially higher levels of academic performance and ability.

\section{Conclusion and implications for practice}

The theoretical model shown in Figure 1 provides a framework through which student transition into university study should be understood and managed. The orientation period appears as a time when the student identity and emotional commitment to that identity should be actively targeted, particularly in terms of how university study fits into longer term career goals. The initial weeks of undergraduate study should allow every student the opportunity to experience a positive demonstration of the role associated with being a university student and should allow students the time and opportunity to develop those aspects of the role that are not currently known. It cannot be assumed that students entering undergraduate study know what is required of them in the role of a university student, irrespective of their previous academic performance.

The focus for academic staff during the early weeks of the transition into undergraduate study should be targeted towards promoting the development of an emotional commitment to longer term employment goals and the associated university student identity, rather than the delivery of academic content or having students demonstrate what they do or do not know. The reduction in university student attrition by possession of clear, long term employment goals and where tertiary education is viewed as being more relevant to employment opportunities has been previously described in the academic literature (Barefoot, 2004; Hirschy, Bremer, \& Castellano, 2011; Metzner, 1989). 
The most important aspect of this approach to theorising the identity-related processes that influence the decision to continue or discontinue university study is that the emotional commitment is associated with the individual's identity, not with the associated role. This view has a number of implications that are important when dealing with students in academic transition. Firstly, attempts to support students in transition that address the academic role aspect only-for example, study behaviours, time management-have a limited capacity to influence the process. That is, simply instructing someone on how to be a university student by performing the required role will not suffice. Any instruction that targets the skills associated with the academic role must also involve an appropriately supported opportunity for the student to demonstrate some form of mastery in the application of these skills in order to develop and strengthen the emotional commitment to their academic identity. Usher and Pajares (2008), in a literature review intended to identify sources of academic self-efficacy, highlighted that this mastery does not need to be demonstrated in academically challenging situations.

Under this framework, the goal for university staff is not only to work with students to strengthen the new academic identity of being a university student but also to develop the associated academic role during the transition period into undergraduate study, rather than the delivery of subject content and/or assess the "worthiness" of the individual to be a university student through assessment. The potential for negative consequences due to the stress of preparing for assessment and receipt of assessment results during a transitional period before students are adequately prepared is evident. Where assessment is utilised during academic transitions, such as entry into university study, it should also be formative in nature and directed towards student learning. The use of non-traditional forms of assessment appears warranted to avoid the angst often associated with examinations and assignments.
Considering that identity change is a slow process (Burke, 2006; Marcia, 1980), the timing and manner of the introduction of contexts and/or assessment that challenge the student in transition need to be considered carefully.

The framework emphasises that the process of identity formation, the development of emotional commitment to an identity and the interpretation of the quality of the performance of the associated role occur within the social context of the student (Ingleton, 1999; Skaalvik \& Skaalvik, 2002; Stryker \& Burke, 2000). The social context therefore has the capacity to either support or challenge identity formation, depending on the situation. For this reason, there needs to be early opportunities for each student to develop strong, supportive relationships with peers through orientation programs at both the university and individual course level. Even more importantly, the academic staff who instruct courses that involve a substantial number of students transitioning into university, should be carefully chosen. Such staff should possess or given the opportunity to develop a strong studentcentered, socio-cultural philosophy of education with appropriate training directed towards understanding the processes involved in supporting students in transition.

It could be argued that the approaches described here may lead to a reduction in academic rigour and the quality of courses will suffer. This is not considered to be the case. Rather, it is proposed that all professional educators, which includes any academic or professional staff engaged in instructing undergraduate students in transition irrespective of their particular area of expertise, have a duty to ensure that all students are given the opportunity to maximise their educational opportunities. This requires educators to deliver an appropriately differentiated program that caters for individual differences and takes into account the challenges that students in transition face. It is not what students can do at the commencement of a course that indicates 
academic rigour, but what they can do at completion. Taking the time to support students through transition by assisting them to develop a strong emotional commitment to an appropriate university student identity and to be well equipped to perform the university student role, will ensure that they are equipped to learn at their optimal pace and meet the demands of a university education.

\section{References}

Allen, B. (2010). Australia. In B. Blaardingerbroek \& N. Taylor (Eds.), Getting into varsity: Comparability, convergence and congruence (pp. 71-91). Amherst, NY: Cambria Press.

Baxter, A., \& Britton, C. (2001). Risk, identity and change: Becoming a mature student. International Studies in Sociology of Education, 11(1), 87-104. doi: 10.1080/09620210100200066

Biggs, M. (2009). Self-fulfilling prophecies. In P. Bearman \& P. Hedstrom (Eds.), The Oxford Handbook of Analytical Sociology (pp. 294-314). Oxford, UK: Oxford University Press.

Bong, M., \& Clark, R. (1999). Comparison between selfconcept and self-efficacy in academic motivation research. Educational Psychologist, 34(3), 139-153.

Bong, M., \& Skaalvik, E. (2003). Academic self-concept and self-efficacy: How different are they really? Educational Psychology Review, 15(1), 1-40. doi: 10.1207/s15326985ep3403_1

Bosma, H., \& Kunnen, W. (2001). Determinants and mechanisms in ego identity development: A review and synthesis. Developmental Review, 21(1), 39-66. doi: 10.1006/drev.2000.0514

Bronfenbrenner, U. (2009). The ecology of human development: Experiments by nature and design. Cambridge, MA: Harvard University Press.

Burke, P. (2006). Identity change. Social Psychology Quarterly, 69(1), 81-96. doi: 10.1177/019027250606900106

Burke, P., \& Reitzes, D. (1981). The link between identity and role performance. Social Psychology Quarterly, 44(2), 83-92. doi: 10.2307/3033704

Burke, P., \& Reitzes, D. (1991). An identity theory approach to commitment. Social Psychology Quarterly, 54(3), 239-251. doi: 10.2307/2786653

Byrne, B. (1984). The general/academic self-concept nomological network: A review of construct validation research. Review of Educational Research, 54(3), 427-456. doi: 10.3102/00346543054003427
Callero, P. (1985). Role-identity salience. Social Psychology Quarterly, 48(3), 203-215. http://dx.doi.org/10.2307/3033681

Choi, N. (2005). Self-efficacy and self-concept as predictors of college students' academic performance. Psychology in Schools, 42(2), 197-205. doi: 10.1002/pits. 20048

Collier, P., \& Morgan, D. (2008). "Is that paper really due today?": Differences in first-generation and traditional college students' understandings of faculty expectations. Higher Education, 55(4), 425446. doi: 10.1007/s10734-007-9065-5

Debenham, J., \& May, J. (2005). Making connections: A dialogue about learning and teaching in a tertiary enabling program. Australian Journal of Adult Learning, 45(1), 82-104.

Deci, E., \& Ryan, R. (1985). Intrinsic motivation and selfdetermination in human behavior. New York, NY: Plenum. http://dx.doi.org/10.1007/978-1-48992271-7

Gibbons, M., Limoges, M., Nowotny, H., Schwartzman, S., Scott, P., \& Trow, M. (2004). The new production of knowledge: The dynamics of science and research in contempory societies (8th ed.). London, UK: Sage.

Hattie, J. (2014). Self-concept. New York, NY: Psychology Press.

Hoelter, J. (1983). The effects of role evaluation and commitment on identity salience. Social Psychology Quarterly, 46(2), 140-147. http://dx.doi.org/10.2307/3033850

Ingleton, C. (1999). Emotion in learning: A neglected dynamic. Paper presented at the HERDSA Annual International Conference, Melbourne, Australia.

Jardine, A., \& Krause, K-L. (2005). Once they arrive how do we keep them? Student persistence research and implications for the retention of non traditional students. Paper presented at the Enhancing Student Success Conference, Newcastle, Australia.

Krause, K-L., Hartley, R., James, R., \& McInnis, C. (2005). The first year experience in Australian universities: Findings from a decade of national studies. Canberra, Australia: Deparment of Education, Science and Training.

Leppel, M. (2002). Similarities and differences in the college persistence of men and women. The Review of Higher Education, 25(4), 433-450. doi: $10.1353 /$ rhe. 2002.0021

Luzeckyj, A., King, S., Scutter, S., \& Brinkworth, R. (2011). The significance of being first: A consideration of cultural capital in relation to "first in family" student's choices of university and program. A Practice Report. The International Journal of the First Year In Higher Education, 2(2), 91-96. doi: 10.5204/intjfyhe.v2i2.89 
Marcia, J. (1980). Identity in adolescence. Handbook of Adolescent Psychology, 5, 159-187.

Marsh, H. (1990). The structure of academic self-concept: The Marsh/Shavelson model. Journal of Educational Psychology, 89(4), 623-636. doi: 10.1037/00220663.82.4.623

Marsh, H., \& Yeung, A. (1997). Causal effects of academic self-concept on academic achievement: Structural equation models of longitudinal data. Journal of Educational Psychology, 89(1), 41-54. doi: 10.1037/0022-0663.89.1.41

McMillan, J. (2005). Course change and attrition from higher education. LSAY Research Report Number 39. Melbourne, Australia: Australian Council for Educational Research.

Metzner, B. S. (1989). Perceived quality of academic advising: The effect on freshman attrition. American Educational Research Journal, 26(3), 422-442. http://dx.doi.org/10.3102/00028312026003422

Moller, J., Pohlmann, B., Koller, O., \& Marsh, H. (2009). A meta-analytic path analysis of the internal/external frame of reference model of academic achievement and academic self-concept. Review of Educational Research, 79(3), 1129-1167. http://dx.doi.org/10.3102/0034654309337522

Pekrun, R., Goeta, R., Titz, W., \& Perry, R. (2002). Academic emotions in students' self-regulated learning and achievement: A program of qualitative and quantitative research. Educational Psychologist, 37(2),

91-105. http://dx.doi.org/10.1207/S15326985EP3702 4

Purkey, W. (1988). An overview of self-concept theory for counselors. Ann Arbor, MI: ERIC Clearinghouse on Counseling and Personal Services.

Reynolds, W. (1988). Measurement of academic selfconcept in college students. Journal of Personality Assessment, 52(2), 223-240. doi: $10.1207 /$ s15327752jpa5202_4

Schunk, D. (1991). Self-efficacy and academic motivation. Educational Psychologist, $26(3$ \& 4), 207-231. http://dx.doi.org/10.1080/00461520.1991.965313 $\underline{3}$

Skaalvik, E., \& Skaalvik, S. (2002). Internal and external frames of reference of academic self-concept. Educational Psychologist, 37(4), 233-244. http://dx.doi.org/10.1207/S15326985EP3704 3

Sparks, P., \& Guthrie, C. (1998). Self-identity and the theory of planned behavior: A useful addition or an unhelpful artifice? Journal of Applied Social Psychology, 28(15), 1393-1410. http://dx.doi.org/10.1111/i.15591816.1998.tb01683.x

Sparks, P., \& Shepherd, R. (1992). Self-identity and the theory of planned behavior: Assessing the role of identification with "Green Consumerism." Social
Psychology Quarterly, 55(4), 388-399. http://dx.doi.org/10.2307/2786955

Stryker, S., \& Burke, P. (2000). The past, present and future of an identity theory. Social Psychology Quarterly, 63(4), 284-297. http://dx.doi.org/10.2307/2695840

Terry, D., Hogg, M., \& White, K. (1999). The theory of planned behaviour: Self-identity, social identity and group norms. British Journal of Social Psychology, 38(3), 225-244 http://dx.doi.org/10.1348/014466699164149

Tett, L. (2000). "I'm working class and proud of it" Gendered experiences of non-traditional participants in higher education. Gender and Education, 12(2), 183-194. http://dx.doi.org/10.1080/09540250050009993

Usher, E., \& Pajares, F. (2008). Sources of self-efficacy in school: Critical review of the literature and future directions. Review of Educational Research, 78(4), 751-796. http://dx.doi.org/10.3102/0034654308321456

Waller, R. (2006). "I don't feel like 'a student', I feel like 'me'!": The over-simplification of mature learners' experience(s). Research in Post-Compulsory Education, 11(1), 115-130. http://dx.doi.org/10.1080/13596740500508019

Wylie, J. (2004). The influence of self-concept on nontraditional student persistence in higher education. (Unpublished doctoral thesis), University of Western Sydney, Sydney, Australia.

Wylie, J. (2005, December). Non-traditional student attrition in higher education: A theoretical model of separation, disengagement then dropout. Paper presented at the Annual Conference of the Australian Association for Research in Education, Parramatta, Australia.

Wiley, M. (1991). Gender, work, and stress: The potential impact of role-identity salience and commitment. Sociology Quarterly, 32(4), 495-510. doi: 10.1111/j.1533-8525.1991.tb00150.x

Willans, J., \& Seary, K. (2007). "I'm not stupid after all" Changing perceptions of self as a tool for transformation. Australian Journal of Adult Learning, 47(3), 432-452. 